\title{
YouTube as a Recruitment Tool? A Reflection on Using Video to Recruit Research Participants
}

\section{Profiling Emerging Research Innovations}

\author{
Suzanne Culshaw \\ Dr, University of Hertfordshire, Hatfield, UK \\ suzanne.culshaw@btinternet.com
}

\begin{abstract}
This article presents an innovative, video-based approach to the recruitment of research participants. A YouTube video was created and uploaded as part of a doctoral study exploring what it means to be struggling as a teacher. Following a review of the recruitment literature, which highlights a general lack of attention paid to the challenges of recruitment, the author explores the approach she took in planning the video. The video was the main promotional tool for the study and was communicated via Twitter and email. She also presents online survey findings on the perceived impact and influence of the video; the visual format, informal tone and the ability to see the researcher in person were rated very positively. A reflective analysis of the video transcript follows drawing on the literature as well as the survey findings. She concludes that video-based recruitment can be an inexpensive but powerful tool which allows a human connection with the researcher early on in the research process.
\end{abstract}

\section{Keywords}

emerging research innovations - recruitment - YouTube - video - approachability innovative - struggling - participants 


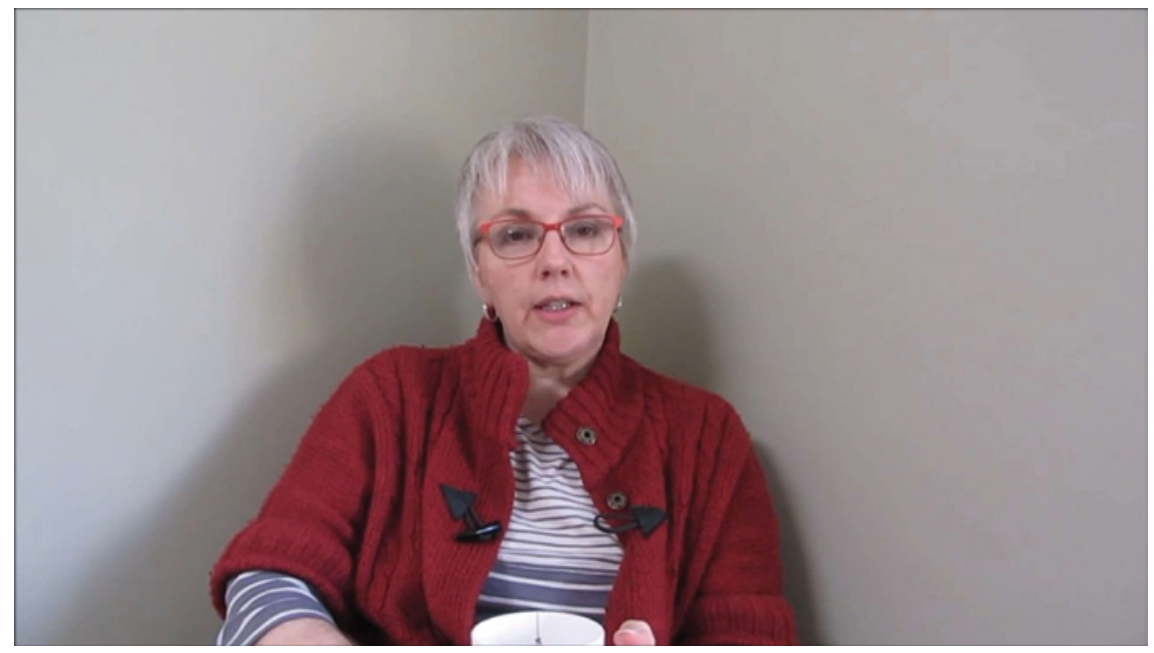

FEATURE Suzanne Culshaw's article comprises a video, which can be viewed here (and here).

- This article is part of the special topic 'Profiling Emerging Research Innovations', edited by Elaine Khoo.

\section{Introduction}

This article presents an innovative recruitment strategy used in a doctoral study. I wanted to recruit educators working in the English secondary school system to participate in research interviews and who would be prepared to share with me their experiences of struggling as a teacher. The research question - what it feels like to be struggling as a teacher - required a particularly sensitive research design. I was keen to come across to potential participants as both approachable and compassionate and felt that a more personal approach to recruitment was required. I wanted to establish a personal connection with potential participants early on in the research process. To this end, I created and uploaded a short YouTube video.

My research found that struggling - as a teacher - is experienced as a temporary, fractured state. Dimensions of struggling include heightened bodily symptoms and it is associated with negative moods and emotions. Struggling can also involve a damaged self-view, a reduced sense of controllability and may lead to impaired performance (Culshaw, 2019a). I adopted an innovative approach, not just for the recruitment of participants, but in terms of the research methodology generally. I used an arts-based method, collage, to explore what it means to be struggling and participants expressed their experience of 
struggling by placing and moving a range of arts and crafts materials as their thinking developed. I have written elsewhere about the power of collage as a research method (Culshaw, 2019b).

In this article I present first a short review of a specific section of the recruitment literature, which I position within the context of the research design for this study. Then I outline the recruitment approach I adopted. I provide a forensic exploration of the specific method I used - a YouTube video - and reflect on its merits as a recruitment tool drawing on survey feedback. I close with an outline of the possible limitations of using this method and suggestions for further research.

\title{
2 Recruitment of Participants: the Literature
}

I undertook a search of the recruitment of research participants literature in Google scholar, with a specific focus on the use of video, the internet and social media in the recruitment of participants. Search terms included:

\author{
promoting research participation online \\ participant recruitment challenges (teachers) \\ recruiting participants online YouTube \\ recruiting participants video
}

A review of abstracts led me to rejecting several publications from the review process, as their focus was more on the use of social media for data collection purposes rather than the recruitment of participants. The search yielded 15 results for review, from a range of disciplines including medical education, psychiatry, social research methodology and occupational rehabilitation. The recruitment literature reviewed here included four systematic reviews. This article adds to that literature and makes a contribution to recruitment methodology generally, and in educational research more specifically. A list of the 15 reviewed publications is included in the Appendix.

Recruitment in research is defined as the dialogue which takes place between an investigator and a potential participant, prior to the initiation of the consent process (Kaba \& Beran, 2014; Patel, Doku \& Tennakoon, 2003). It is essential to consider a recruitment methodology when designing a research project as the methods used influence the success of the research (Derrick, Elsieo-Jaye, Hanny, Britton \& Haddad, 2017). In many cases, multiple - rather than single - recruitment strategies are used (e.g. Ibrahim \& Sidani, 2014; Luck, Chok \& Wilkes, 2017). Some suggest (e.g. Kaba \& Beran, 2014; Patel et al., 2003) that recruitment is the most challenging aspect of any study and yet it is a key 
determinant of the results (Kaba \& Beran, 2014). Others bemoan the lack of attention given to recruitment in the literature (e.g. Lysaght, Kranenburg, Armstrong \& Krupa, 2016; Nasser, Grady \& Balke, 2011). Few authors have "dissected their studies" (Luck et al., 2017, p. 44) to review their recruitment strategies and it is not always clear how researchers accessed potential participants. Recruitment is not adequately or widely reported in many research publications as I found when searching the literature for this article. Kaba and Beran (2014, p. 578) state that "researchers often spend less than a few sentences summarising access to the sample".

Details highlighting the processes used to engage participants often remain unclear (Lysaght et al., 2016). Guidance and tips (e.g. Kaba \& Beran, 2014) are thin on the ground despite an appeal from Lysaght et al. for light to be shone on the specifics of recruitment to "enhance methodological transparency and inform practice" (2016, p. 136). Innovative strategies have the potential to engage participants' attention (Kaba \& Beran, 2014) yet even less attention has been given to developing such methods (Nasser et al., 2011). Rife et al. suggest that social media (in this case Facebook) are a "promising new (recruitment) space for social scientists" (2016, p. 80). In their systematic review, Whitaker et al. (2017) found that Facebook as a recruitment method was faster and cheaper and had the potential to improve participant selection in harder-toreach demographics. However, only one publication (Khatri, Chapman, Glasbey, Kelly \& Nepogodiev, 2015) adopted the approach I took, i.e. a purposemade YouTube video - which they reported as a "novel feature of the study" (p. 7) - as part of their recruitment strategy. In summary, then, there is a paucity of literature (Khatri et al., 2015) on recruitment and insufficient methodological attention (Kaba \& Beran, 2014) has been paid to the challenges, opportunities and practicalities of different recruitment approaches.

Consideration of an appropriate recruitment strategy for my study was part of the wider research design process which took into account the particularly sensitive nature of the research question. Research which delves into deeply personal experiences can be stressful for the participant and the researcher (Dickson-Swift, James, Liamputtong, 2008; Lee \& Renzetti, 1993). Sensitive research topics can deepen the emotional connection between the researcher and participant, as both co-construct the narrative history (e.g. Fahie, 2014). It was clear to me that I would need to establish a trustful relationship and rapport with potential participants from the outset. Video can be one step in establishing trust, as participants get to see the researcher and get a sense of their sincerity, credibility and enthusiasm (Hendrickson, 2007). Hendrickson (2007) also describes how video can be used for promoting studies, recruiting participants and gaining consent, but suggests that video-based recruitment methods are generally difficult to evaluate, rarely utilised and/or underreported. 
Integrity is a key element of the research process and a vital characteristic of the researcher; clearly, the application for ethics approval for this study had to consider the sensitive nature of the research topic and assess the risk of potential harm to participants. Confidentiality and anonymity were particularly pertinent as was my duty of care to participants; I provided details of external, professional support at all interviews with participants. The ethics application process was underpinned by guidelines set out by the British Educational Research Association (BERA, 2011) and approved by the relevant ethics committee at my university.

In the section below, I describe the approach I adopted when recruiting participants for a study exploring what it means to be struggling as a teacher.

Recruiting teachers who would be prepared and able to talk about their experience of struggling had the potential to be difficult but was central to the success of this research. Careful consideration had to be given to the approach I took, how I worded any recruitment documentation and, more practically, how I would access potential participants. Gaining access to the sample population is a key consideration (Kaba \& Beran, 2014) once the inclusion and exclusion criteria for participation have been decided (Patel et al., 2003).

Establishing a rapport with the participants was always going to be crucial and potential participants needed to be able to relate to the person they would be opening up to. Being amenable and approachable are dimensions of having good interpersonal skills and are some of the key attributes highlighted as important in the literature (e.g. Kaba \& Beran, 2014; Patel et al., 2003). Non-verbal cues and affect-based messages are also more likely to attract potential participants (Kraichy \& Chapman, 2014). Researcher credibility is also mentioned as essential as it influences people's willingness to participate (Hendrickson, 2007; Lysaght et al., 2016). Kaba and Beran suggest that introductions are best made "in person" (2014, p. 582) and researchers should not underestimate the "personal touch" (Luck et al., 2017, p. 44). Kaba and Beran also suggest that if the researcher has "excellent networking skills" they should "use this strength" (2014, p. 583). It is, however, important to remain mindful of ethical considerations and the possibility of pressurising potential participants into taking part (Luck et al., 2017).

Taking this into account, I created a short recruitment video which I posted on YouTube and shared on social media, mainly through my Twitter account and my blogsite. The video lasted three minutes and showed me in my office holding a cup of tea, talking about the rationale for my study and the kind of 
teachers I was hoping to attract. My main reason for posting the video was to be seen as approachable, credible and sensitive. I also liked that it was a way to provide a consistent presentation (Hendrickson, 2007) of a "standardised message" to all potential participants (Khatri et al., 2015, p. 7). I hoped viewers would sense that we shared a similar background and professional concerns (Caldwell et al., 2010; Ibrahim \& Sidani, 2014; Luck et al., 2017). The video attracted about 100 views within two weeks of being posted and a number of participants mentioned that they had watched it. I subsequently conducted a separate survey to elicit feedback about the merits of this particular approach to recruitment. Results of the survey are presented below.

The only other study I was familiar with which used a purpose-made YouTube video is a 2015 clinical study targeting medical students. It combined the use of YouTube, Twitter, Facebook and a website to recruit participants for a "national, multicentre cohort study" in England (Khatri et al., 2015, p. 3). The research team created an introductory, narrated, step-by-step video to explain the project and protocol to potential participants. A link to the registration form was placed in the comments section. The video was 7:53 minutes long and is no longer available for viewing. This was a large-scale project in comparison to my study and involved a team of researchers. Similar to that project, however, I found this approach "easy and intuitive to use... as it provides an accessible medium by which to distribute" (Khatri et al., 2015, p. 7) information about the study. It was also "far less time intense" than other possible approaches (Khatri et al., 2015, p. 7).

My video was the main promotional tool; the main channel of communication to potential participants was via emails to secondary schools I know within about 40 miles of where I live. The text of the emails included a link to the YouTube video. Information for research participants can often look academic and professional but the text can be difficult to read (Haynes, Chen, Wincott, Dayanandan, Lay, Parish, Bowman, Landray \& Armitage, 2019); the language I used in both the video and all written communications was "pitched at a level that can be understood by the potential participants" (Patel et al., 2003, p. 231) whilst also adhering to the "usual rules of written professional correspondence" (Kaba \& Beran, 2014, p. 580). The first challenge, according to Lysaght et al., is to identify the "best first point of contact" (2016, p. 136) and I identified the need to circulate information about the study via the use of gatekeepers, in this case school leaders. The emails were sent either to the Headteacher or to a Senior Leader with responsibility for staff training and/or wellbeing. In all correspondence with gatekeepers and potential participants, I emphasised my professional experience as a teacher and, to some extent, my personal experience of struggling. I also made it clear that any further contact was to be made directly with me. It was important to make the initial presentation 
"palatable" (Lysaght et al., 2016, p. 136) by creating a "buzz" about my research and explaining how it might directly impact teachers (Kaba \& Beran, 2014, p. 580 ). I was not offering any particular incentives to participants but hoped that their intrinsic motives for getting involved might include "curiosity, altruism... and knowledge" (Kaba \& Beran, 2014, p. 583).

I was mindful of the fact that any willingness to participate can depend on the perceived "attractiveness of the research question" (Nasser et al., 2011, p. 1334) and that participants will only take part if they can identify with and "understand the validity and relevance" of the study (Kaba \& Beran, 2014, p. 581). Relevance of the topic and applicability to personal context are factors which can influence the decision to participate (Caldwell, Hamilton, Tan, Craig \& Boutron, 2010; Luck et al., 2017). The topic of struggling as a teacher is both relevant and timely in the English secondary state school system. However, some researchers struggle with recruitment of participants (Rife, Cate, Kosinski \& Stillwell, 2016) and I was aware that under-enrolment on the study would affect the contribution to knowledge I was seeking (Nasser et al., 2011). Successful recruitment is critically dependent on the initial contacts made (Patel et al., 2003) and this underpinned the rationale for the approach I took. Initial concerns about not recruiting sufficient participants were soon allayed when I was contacted by more than twenty potential participants. It is not possible to report the direct influence of the video as data were not collected on how many participants had or had not viewed the video.

I turn now to a reflective analysis of the recruitment video and take a forensic approach to the video transcript. I also present feedback from an online survey conducted after completion of the study. First, however, I describe the thinking behind the creation of the video itself.

\section{The Recruitment Video: a Reflective Analysis}

In this section I describe the recruitment video I uploaded to YouTube and reflect on its relative effectiveness. The video was filmed in one take, after preparing some notes to refer to if needed and with helpful guidance from my son who was regularly vlogging at the time. I was keen to aim for multiple exposures and wanted to use a "variety of different methods (to) engage multiple stakeholders and collaborators" (Kaba \& Beran, 2014, p. 584) to increase the "likelihood of participation" (Kaba \& Beran, 2014, p. 579). The video was pivotal and would act as more than a useful "adjunct to traditional methods" (Khatri et al., 2015, p. 2) such as email and personal networks.

The video was created in March 2017 (posted on YouTube: 30/03/2017), as part of the recruitment strategy for my doctoral study (Culshaw, 2019a). I was 
looking for teachers who would be willing to talk about their experience of struggling. The video can be viewed here: https://www.youtube.com/watch?v= 3S_wlotcuF4

The rationale for the video was to appear approachable, credible and sensitive. I planned it to be a clear, concise and consistent summary of the project as well as an opportunity for potential participants to see who I was; an "inperson introduction," (Kaba \& Beran, 2014, p. 582) albeit on screen. I hoped to show a "caring and compassionate attitude" (Patel et al., 2003, p. 234) and to be "passionate about [my] research" (Kaba \& Beran, 2014, p. 581). When potential participants made an initial approach, supplementary written details were provided.

Patel et al. suggest that the language used should be "pitched at a level that can be understood by potential participants" (2003, p. 231). My background as a teacher gave me an insider view and allowed me to gauge the type of language to use. I was particularly keen not to alienate viewers by using overly academic language. Indeed, throughout the study I adopted a more informal register in written and spoken correspondence. This goes, perhaps, against the advice of some who suggest adhering to the "usual rules of written professional correspondence" (Kaba \& Beran, 2014, p. 580). I maintain that my conduct and correspondence remained professional, if unconventional, throughout. The text below is an extract from the introductory email which accompanied the video and is an example of the written register I used. It also mirrors the style of spoken language used in the video:

\section{Looking for participants for a PhD research study!}

I am a former teacher and now full-time PhD student at the University of Hertfordshire. My research is looking at the experience of struggling what it feels like and what it means to be struggling as a teacher. If you feel that this is something you could talk to me about, in confidence, then I'd love to hear from you. If you'd like to know a bit more about my study and what taking part would involve, then please follow the links below. My contact details are included at the bottom of the blog, and below.

\section{Blog: https://musingmindfully.wordpress.com/2017/03/23/its-good -to-talk/}

YouTube: https://youtu.be/3S_wlotcuF4

Twitter: follow and DM @SuzanneCulshaw

Email: sc15agr@herts.ac.uk 
The literature reviewed above purports to provide practical guidance on how to recruit participants and also draws on the experience of the authors (e.g. Kaba \& Beran, 2014; Khatri et al., 2015). Indeed, Kaba and Beran outline twelve tips to "improve the quantity and efficiency of recruitment to provide highquality outcomes and evidence on the effectiveness of research" (2014, p. 583). Nasser et al., however, highlight the lack of attention on how to implement "best practices for achieving participant recruitment" (2011, p. 1334). Moreover, there appears to be a lack of empirical data from participants on their experienceof recruitment. In their systematic review, Ibrahim and Sidani (2014) found that less than half of the reviewed publications reported the effectiveness of recruitment strategies; Caldwell et al. (2010) report, too, that recruitment findingstend to be inconclusive and not generalisable. In my study, I had not initially intended to collect feedback from the participating teachers about their recruit ment experience nor the factors influencing their willingness to participate. To address this, in retrospect, and to explore more forensically the potential of a video-based approach to recruitment, I subsequently designed an online survey. This survey was not intended to be completed by participants in my study.

\section{$5 \quad$ Post-study Survey Findings}

A survey was created with a view to eliciting feedback on the specific recruitment video uploaded to YouTube in March 2017. The survey was conducted after completion of the study and its sole purpose was to gauge responses to this style of recruiting research participants. The respondents were anonymous and were highly unlikely to have been participants in the original study. It was a small-scale survey, designed to elicit perceptions and impressions of a video-based approach.

The survey consisted of six questions and the link was shared via my Twitter account. The tweet was directed at my followers (approx. 4,00o people and organisations predominantly in the fields of educational leadership, teaching and/or educational research). It was retweeted 14 times and had almost 200 engagements, according to the Tweet Analytics.

\section{Tweet 1:}

Got 5 mins to watch short video \& answers few questions for me, please? Looking for impressions, to help with journal article I'm writing. Video link. Survey link. (No prior knowledge of research participation or methods needed.) Please RT. 
Tweet 2 (2 days later):

Thanks for the responses so far. One last push today... it literally takes 5 mins. All feedback gratefully received, as it will help inform a recruitment strategy for a new project (as well as a journal article I'm writing).

There were 17 returns and, from the responses, it was clear that respondents had engaged with the video to some extent at least. The wording of the questions, the type of questions and a summary of the results are presented in Table 1.

TABLE 1 Post-study online survey to elicit feedback on video as a recruitment tool

Question Question

No.

1.

Having watched the video, try to sum up

your impressions in just

a few words

\section{Question type / Results \& Themes \\ No. of responses}

Open comments, n:17

(1)

2.

3.

4.

\footnotetext{
Having watched the video, I would be

Questions 2-5: 5-point Likert scale:

interested in finding out strongly dis-

more about participat-

agree (1) - strongly

ing in this study

agree (5), n:1 7

I find the visual format

appealing (e.g. com-

pared with a written

information sheet

outlining the study)

I like seeing the researcher in person
}

15 agree (3 agree; 12 strongly agree) confidence; shows who the researcher is; empathetic; clear; simple; trustworthiness; nice body stance; good idea; concise; articulate; strikes a chord; genuine; warm tone; non pressurising; helpful; informal; approachable; engaging; detailed; unique; authentic; open; innovative; effective

- Personal characteristics of researcher

- Visibility of researcher

12 agree (7 agree; 5 strongly agree) 15 agree (4 agree; 11 strongly agree) 
Question Question

No.
Question type / Results \& Themes

No. of responses

5. I like the informal tone

of the video (e.g

compared with a more

formal, academic tone)

6. Any other feedback,

Open comments,

Accessible; real; perfect recruiting thoughts, challenges

n:15

about the use of a video

like this to recruit

research participants

14 agree (4 agree; 10 strongly agree)

medium; human connection with researcher is important; I'd consider (this approach); great idea and way to do it; much more powerful; helps show why the research matters; focus is defined; seeing the researcher - relatable; accessible, up front and honest; might encourage participation; I may try this in the future; keep it shorter (1-2 mins); would also want written formal information; informal spoke people's language; try to keep it under 2 minutes; you didn't smile; content was great; interested to know where you shared it; ensure it receives enough publicity?; you look right to your notes - explain that (to viewers)?

- Personal characteristics of researcher

- Visibility of researcher

- Practical aspects of the video

- $\quad$ Appropriateness of video-based approach

Themes emerging from the survey findings include the importance of the personal characteristics of the researcher, the visibility of the researcher, practical aspects of a video-based approach and the appropriateness of the approach. 
Survey questions two to five were all framed as positive statements and allowed respondents to choose on a 5-point Likert scale between strongly disagree, agree, neither disagree nor agree, agree and strongly agree. I am aware of the dangers of acquiescence bias in wording the questions this way. However, the comments in the open questions ( 1 and 6 ) do not contradict the overall positive experience of the video. Useful critical feedback included not referring to my notes during the video and reducing the length of the video to under two minutes. Ideal video length is perhaps a topic requiring further research (Hendrickson, 2007). In one paper (Gendron, King Seymour \& Welleford, 2016), a focus group was used to help choose what to include in the video. Developing the script was a key feature of the use of video in another study and it might have been useful for me to seek third party feedback about the script (Hendrickson, 2007).

In terms of feedback about the visual format, being able to see the researcher in person and the informal tone of the video (questions $3-5$ ), responses were overwhelmingly positive. Qualitative comments included 'much more powerful, 'helps show why the research matters' and 'human connection with researcher is important.' Useful critical feedback included wanting to know how and where the video was shared and ensuring it reached a sufficiently diverse network of potential participants.

In this section I use the recruitment literature and the survey findings as an analytical lens to explore the video transcript. Below is the full transcript of the 3-minute video from which I have highlighted a selection of phrases for further analysis. I then present these phrases with reference to the literature and by incorporating feedback from the online survey.

Hello. I'm Suzanne ( 1 ) and I'm doing a PhD in education with the University of Hertfordshire (2). I was hoping to talk to you about my research study in which I'll be looking at what it means and what it feels like to be struggling as a teacher. I used to be a secondary school teacher and I was struggling at times (3). It's quite difficult to express exactly what that struggle feels like (4). There are no studies out there that have looked in detail at what it means to be struggling and I guess it would help at this stage to say that what I mean by struggling is when you're not quite coping when you're not quite managing (5). I'm not particularly interested in in looking at what it is that you're struggling with although no doubt all the changes to the education system to GCSE specifications and those kind of things 
may well have triggered something in you which mean that you feel like you are struggling. But actually, I'm interested in what it feels like, that experience of struggling and so if you're prepared to get involved in my research, we'd look in detail at what it means and what it feels like to struggle (6). But, also, there's a little bit perhaps about when the struggling began or when you were not struggling and so that journey between struggling and not-struggling is of interest to me as well. And finally, we'd look to explore the factors which influence the struggling, the ones that help and the ones that hinder. You might find talking about struggling difficult, and I think that's to be expected but equally it can be quite a useful thing to do to have that opportunity to talk to someone about how things are going for you (7). If you feel like you'd like to get involved with my study, then I'd love to hear from you (8). My contact details will appear at the end. Essentially what it would involve is meeting up with you on two different occasions to talk about your experience (9). Of course, I've got ethics approval from my university to conduct this study and I can guarantee that your data would be kept confidentially and your identity will be anonymised throughout (1o). And, of course, what is important to state is that even if you say you want to get involved and then change your mind then you're free to withdraw at any stage, no reason needed (11). So, if you think that you've got a story to tell me, if you'd like me to hearyour experience of struggling, then I'd love to hear from you (12). Thank you for listening (13).

I have extracted 13 phrases from the video transcript for further elucidation. For ease of reading, I do not include individual references to the literature in the table but am drawing on seven of the most relevant publications reviewed in this article (Derrick et al., 2017; Kaba \& Beran, 2014; Khatri et al., 2015; Lysaght et al., 2016; Nasser et al., 2011; Patel et al., 2003; Rife et al., 2016). Each phrase can be rooted in the literature and/or the survey findings.

Table 2 shows how the highlighted phrases provide a pathway to guide others through the phases of introducing the study and key details they would need to know, to help them decide whether to participate. The phrases emphasise the importance of researchers connecting with potential participants in terms of personal characteristics such as approachability, credibility and empathy. Participants also need to receive sufficient information about the research topic itself and to sense the researcher's enthusiasm for the topic. Finally, they need reassurance about the ethical conduct and practicalities of the research process as well as an appreciation of their willingness to participate. What Table 2 shows, therefore, is a triangulation between the literature and the planning and creation of the YouTube video which has also been confirmed by the retrospective survey findings. 
TABLE 2 Video transcript phrases and reference to the literature and survey findings

Quote from transcript
Literature focus \& survey findings

Informal, approachable

Credibility, reputation

2. PhD in education with the University of Hertfordshire

3. I used to be a secondary school teacher and I Ability to empathise with was struggling at times participants; common concern; co-construction of narratives; motivation and interest

4. It's quite difficult to express exactly what that struggle feels like

Reason for research; no preconceived definition

5. I I $\quad$ uess it would help at this stage to say that what I mean by struggling is when you're not quite coping when you're not quite managing

6. we'd look in detail at what it means and what it feels like to struggle

7. You might find talking about struggling difficult, and I think that's to be expected but equally it can be quite a useful thing to do to have that opportunity to talk to someone about how things are going for you

8. then I'd love to hear from you

9. Essentially what it would involve is meeting up with you on two different occasions to talk about your experience

10. I've got ethics approval from my university to conduct this study and I can guarantee that your data would be kept confidentially and your identity will be anonymised throughout
Attempt at a definition; sharing initial thoughts about the key concept

Use of 'we' to indicate co-construction, participants are seen as 'collaborators' but researcher brings her experience too

Understanding of the sensitivity of the topic; compassionate and caring attitude; duty of care to participants; cathartic / beneficial - as a 'by-product' of participating (Davies \& Gannon, 2006); ethical considerations

Passion and enthusiasm for topic; appreciation for willingness to take part

Practicalities of what participation would involve

Credibility; reputation; duty of care; ethical considerations 
TABLE 2 Video transcript phrases and reference to the literature and survey findings (cont.)

$\begin{array}{ll}\text { Quote from transcript } & \begin{array}{l}\text { Literature focus \& survey } \\ \text { findings }\end{array}\end{array}$

11. if you say you want to get involved and then change your mind then you're free to

Consent; ethical considerations; withdraw at any stage, no reason needed

12. if you think that you've got a story to tell me, if you'd like me to hear your experience of struggling, then I'd love to hear from you

13. Thankyou for listening right to withdraw

Passion and enthusiasm for topic; openness; compassionate and caring attitude Appreciation

In summary, the video attempted to show me, in person, as a credible, trustworthy and caring researcher. It provided a summary overview of the study and an indication of what participation would involve. Ethical considerations were mentioned as well as the right to withdraw. It was a direct, passionate, appreciative appeal to teachers to share their stories of struggling, an experience that I share. The video was viewed over 100 times within just two weeks and I was contacted by over 20 potential participants. I suggest that the characteristics highlighted in Table 2, which are referenced in the recruitment literature and confirmed in the survey findings, need to be inherent if the use of video as a recruitment tool is to be effective.

\section{$7 \quad$ Concluding Remarks}

When I was planning the research design for this study, recruitment was obviously a consideration but not necessarily a key one. I have presented here a "novel feature" and a potentially "new modality for ... recruitment" (Khatri et al., 2015, p. 7, 2) which I suggest is suitable for lone researchers like myself. The video I created and uploaded to YouTube has now been viewed over 200 times. However, I will never know exactly how many participants watched or were influenced by the recruitment video I shared. This is a limitation I acknowledge. At the time, it was not my intention to collect data relating to the impact or influence of that particular recruitment tool, although some participants mentioned that they had watched it. Researchers, including myself, would do well to plan to elicit and learn from feedback on what actually influenced people's willingness to participate. 
This was a small-scale study in the field of education, with one researcher and limited budget. Creating the video was neither time-consuming nor expensive. The online survey which was conducted after completion of the study has afforded feedback into the potential for using video for recruiting research participants. Given the importance of accessing participants for the success of research and the validity of research outcomes, further research into the potential influence and power of video-based recruitment approaches would be welcome.

\section{Acknowledgements}

I am very grateful to the School of Education, University of Hertfordshire, England, for providing me with a fully-funded 3-year PhD studentship, which supported me whilst I conducted my doctoral research.

\section{References}

BERA. (2011). BERA Ethical Guidelines: British Educational Research Association Ethical Guidelines. British Educational Research Association.

Caldwell, P. H. Y., Hamilton, S., Tan, A., \& Craig, J. C. (2010). Strategies for Increasing Recruitment to Randomised Controlled Trials: Systematic Review. PLoS Medicine, $7(11), 1-16$.

Culshaw, S. (2019a). An exploration of what it means to be struggling as a secondary teacher in England. University of Hertfordshire.

Culshaw, S. (2019b). The unspoken power of collage? Using an innovative arts-based research method to explore the experience of struggling as a teacher. London Review of Education, 17(3), 268-283.

Derrick, J. L., Eliseo-Arras, R. K., Hanny, C., Britton, M., \& Haddad, S. (2017). Comparison of internet and mailing methods to recruit couples into research on unaided smoking cessation. Addictive Behaviors, 75, 12-16.

Dickson-Swift, V., James, E. L., \& Liamputtong, P. (2008). What is sensitive research. Undertaking Sensitive Research in the Health and Social Sciences: Managing Boundaries, Emotions and Risks, 1, 1-10.

Fahie, D. (2014). Doing sensitive research sensitively: Ethical and methodological issues in researching workplace bullying. International Journal of Qualitative Methods, 13(1), 19-36.

Gendron, T. L., King Seymour, L., \& Welleford, E. A. (2016). Catch a Glimpse of Me: The development of staff videos to promote person-centered care. Dementia, 15(5), 1289-1294. 
Haynes, R., Chen, F., Wincott, E., Dayanandan, R., Lay, M. J., Parish, S., Bowman, L., Landray, M. J., \& Armitage, J. (2019). Investigating modifications to participant information materials to improve recruitment into a large randomized trial. Trials, 2o(1), $1-6$.

Hendrickson, S. G. (2007). Video Recruitment of Non-English-Speaking Participants. Western Journal of Nursing Research, 29(2), 232-242.

Ibrahim, S., \& Sidani, S. (2014). Strategies to Recruit Minority persons: A Systematic Review. Journal of Immigrant and Minority Health, 16(5), 882-888.

Kaba, A., \& Beran, T. (2014). Twelve tips to guide effective participant recruitment for interprofessional education research. Medical Teacher, $36(7), 57^{8-584}$.

Khatri, C., Chapman, S. J., Glasbey, J., Kelly, M., Nepogodiev, D., Bhangu, A., Fitzgerald, J. E., \& on behalf of the STARSurg Committee. (2015). Social Media and Internet Driven Study Recruitment: Evaluating a New Model for Promoting Collaborator Engagement and Participation. PLOS ONE, $10(3), 1-11$.

Kraichy, D., \& Chapman, D. S. (2014). Tailoring Web-Based Recruiting Messages: Individual Differences in the Persuasiveness of Affective and Cognitive Messages. Journal of Business and Psychology, 29(2), 253-268.

Lee, R. M., \& Renzetti, C. M. (1993). Researching sensitive topics. Sage Publications Newbury Park, CA.

Luck, L., Chok, H. N., \& Wilkes, L. (2017). Nurses as participants in research: An evaluation of recruitment techniques. Nurse Researcher, 25(2), 44-48.

Lysaght, R., Kranenburg, R., Armstrong, C., \& Krupa, T. (2016). Participant Recruitment for Studies on Disability and Work: Challenges and Solutions. Journal of Occupational Rehabilitation, 26(2), 125-140.

Nasser, N., Grady, D., \& Balke, C. W. (2011). Commentary: Improving Participant Recruitment in Clinical and Translational Research. Academic Medicine, 86(11), 1334-1335.

Patel, M. X., Doku, V., \& Tennakoon, L. (2003). Challenges in recruitment of research participants. Advances in Psychiatric Treatment, 9(3), 229-238.

Rife, S. C., Cate, K. L., Kosinski, M., \& Stillwell, D. (2016). Participant recruitment and data collection through Facebook: The role of personality factors. International Journal of Social Research Methodology, 19(1), 69-83.

Whitaker, C., Stevelink, S., \& Fear, N. (2017). The Use of Facebook in Recruiting Participants for Health Research Purposes: A Systematic Review. Journal of Medical Internet Research, 19(8), e290. 


\section{Appendix: List of Reviewed Publications}

1. Caldwell, P. H. Y., Hamilton, S., Tan, A., \& Craig, J. C. (2010). Strategies for Increasing Recruitment to Randomised Controlled Trials: Systematic Review. PLoS Medicine, $7(11), 1-16$.

2. Derrick, J. L., Eliseo-Arras, R. K., Hanny, C., Britton, M., \& Haddad, S. (2017). Comparison of internet and mailing methods to recruit couples into research on unaided smoking cessation. Addictive Behaviors, 75, 12-16.

3. Gendron, T. L., King Seymour, L., \& Welleford, E. A. (2016). Catch a Glimpse of $M e$ : The development of staff videos to promote person-centered care. Dementia, 15(5), 1289-1294.

4. Haynes, R., Chen, F., Wincott, E., Dayanandan, R., Lay, M. J., Parish, S., Bowman, L., Landray, M. J., \& Armitage, J. (2019). Investigating modifications to participant information materials to improve recruitment into a large randomized trial. Trials, $20(1), 1-6$.

5. Hendrickson, S. G. (2007). Video Recruitment of Non-English-Speaking Participants. Western Journal of Nursing Research, 29(2), 232-242.

6. Ibrahim, S., \& Sidani, S. (2014). Strategies to Recruit Minority persons: A Systematic Review. Journal of Immigrant and Minority Health, 16(5), 882-888.

7. Kaba, A., \& Beran, T. (2014). Twelve tips to guide effective participant recruitment for interprofessional education research. Medical Teacher, $36(7)$, 578-584.

8. Khatri, C., Chapman, S. J., Glasbey, J., Kelly, M., Nepogodiev, D., Bhangu, A., Fitzgerald, J. E., \& on behalf of the STARSurg Committee. (2015). Social Media and Internet Driven Study Recruitment: Evaluating a New Model for Promoting Collaborator Engagement and Participation. PLOS ONE, $10(3), 1-11$.

9. Kraichy, D., \& Chapman, D. S. (2014). Tailoring Web-Based Recruiting Messages: Individual Differences in the Persuasiveness of Affective and Cognitive Messages. Journal of Business and Psychology, 29(2), 253-268.

10. Luck, L., Chok, H. N., \& Wilkes, L. (2017). Nurses as participants in research: An evaluation of recruitment techniques. Nurse Researcher, 25(2), 44-48.

11. Lysaght, R., Kranenburg, R., Armstrong, C., \& Krupa, T. (2016). Participant Recruitment for Studies on Disability and Work: Challenges and Solutions. Journal of Occupational Rehabilitation, 26(2), 125-140.

12. Nasser, N., Grady, D., \& Balke, C. W. (2011). Commentary: Improving Participant Recruitment in Clinical and Translational Research. Academic Medicine, 86(11), 1334-1335. 
13. Patel, M. X., Doku, V., \& Tennakoon, L. (2003). Challenges in recruitment of research participants. Advances in Psychiatric Treatment, 9(3), 229-238.

14. Rife, S. C., Cate, K. L., Kosinski, M., \& Stillwell, D. (2016). Participant recruitment and data collection through Facebook: The role of personality factors. International Journal of Social Research Methodology, 19(1), 69-83.

15. Whitaker, C., Stevelink, S., \& Fear, N. (2017). The Use of Facebook in Recruiting Participants for Health Research Purposes: A Systematic Review. Journal of Medical Internet Research, 19(8), e290. 